\title{
CULTURA ORGANIZACIONAL ESCOLAR: APOGEU INVESTIGATIVO NO QUADRO DE EMERGÊNCIA DAS POLÍTICAS NEOLIBERAIS
}

\author{
LEONOR LiMA TORRES
}

\begin{abstract}
RESUMO: Inscrita numa matriz teórica multirreferencial, a problemática da cultura organizacional tem sido objecto de múltiplos desenvolvimentos conceptuais e diversificadas apropriações políticas e ideológicas. No campo da educação e no contexto mais específico das organizações escolares, as abordagens culturais e simbólicas sofreram algumas inflexōes teóricas apenas compreensíveis quando contextualizadas no quadro mais global das políticas internacionais de cariz neoliberal e neoconservador. Neste trabalho, procura-se reflectir criticamente sobre a forma como a problemática da cultura organizacional em contexto escolar passa a ser (re)perspectivada numa altura em que se expandem alguns objectivos e valores políticos associados às ideologias da modernização e da racionalização. Num segundo momento, tomando como ponto de partida a análise de um vasto número de investigaçōes integradas em quatro bases de dados electrónicas de âmbito internacional, debatemos as principais tendências teóricas, conceptuais e metodológicas deste campo de estudo, fazendo sobressair o lugar e o estatuto da escola enquanto contexto privilegiado de investigação, designadamente nos domínios crítico-reflexivos.
\end{abstract}

Palavras-chave: Cultura organizacional. Cultura escolar. Políticas educativas. Sociologia das organizações educativas.

Professora auxiliar e investigadora do Instituto de Educação e Psicologia da Universidade do Minho (Portugal).E-mail: leonort@iep.uminho.pt 
Cultura organizacional escolar: apogeu investigativo no quadro de emergência...

SCHOOL ORGANIZATIONAL CULTURE:

THE PEAK OF RESEARCH IN THE CONTEXT OF NEOLIBERAL POLICIES

ABSTRACT: Within a multi-referential theoretical framework, the issue of organizational culture has been a subject for multiple conceptual developments and different ideological and political appropriations. In the field of education and in the specific context of school organizations, the cultural and symbolic approaches were subjected to some theoretical inflections. These can only be understood in the global framework of international policies of neoliberal and neoconservative nature. First, this paper critically discusses how the issue of organizational culture in school context was put in perspectives at a time when some political-ideological objectives and values were associated to modernization and rationalization ideologies. Based on the analysis of a great number of researches included in four electronic databases with an international scope, it then discusses the main theoretical, conceptual and methodological trends of this field of study, stressing the place and statute of school as a privileged research context, namely in the reflexive and critical domain.

Key words: School organizational culture. School culture. Educational policies. Sociology of educational organizations.

\section{Introdução}

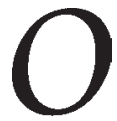

desenvolvimento da cultura organizacional como um objecto de estudo amplamente disputado pelas mais diversas áreas disciplinares assume, a partir da década de 1980, contornos teóricos e epistemológicos complexos quanto à forma, ao conteúdo e ao seu próprio sentido ontológico. Ancorados em diversos (e por vezes contraditórios) quadros teóricos e disciplinares, os estudos sobre a cultura organizacional sofreram um aumento quantitativo, ao mesmo tempo que diversificaram igualmente os contextos e as unidades investigativas, proporcionando ao investigador um amplo e polifacetado campo analítico, só remotamente desvendável por via da reconstrução dos seus sentidos genealógicos.

Entre os diversos contextos organizacionais que têm constituído alvo de análise no domínio das abordagens culturais, a escola emerge, no panorama internacional, como um dos contextos mais estudados, 
sendo mesmo difícil identificar com algum rigor o sector pioneiro no estudo desta problemática, se o sector económico (a empresa), se o sector educativo (a escola). ${ }^{1}$ Em qualquer dos casos, a instituição educativa pública, quer ao nível das escolas não superiores, quer, mais recentemente, ao nível das escolas superiores e/ou universidades, desde cedo se tornou num objecto privilegiado de análise sob o ponto de vista das suas especificidades culturais, o que contraria um certo senso-comum intelectual responsável pela naturalização da ideia de que a moda da cultura escolar constitui um fenómeno recente, uma espécie de reacção tardia aos paradigmas dominantes na empresa.

Num primeiro momento, abordaremos a importância da problemática da cultura organizacional no quadro mais vasto do desenvolvimento contemporâneo das políticas e das ideologias neoliberais e neoconservadoras. Num segundo momento, debruçaremo-nos sobre a investigação científica desenvolvida nas últimas décadas sobre este tema. Para acedermos às agendas investigativas e metodológicas que dominaram a vertiginosa publicação de estudos sobre a cultura organizacional no panorama internacional, consultámos algumas das mais prestigiadas bases de dados electrónicas (UMI, ERIC, ABI-INFORM, ISI), tendo estas permitido subtrair algumas tendências hegemónicas quanto à evolução das publicações, às filiaçôes teórico-conceptuais, ao lugar ocupado pela escola enquanto contexto empírico de investigação, aos autores mais citados, aos contextos sociais e geográficos de produção, entre outros aspectos. Face à diversidade e à riqueza deste manancial de informação bibliográfica, apenas nos limitaremos a destacar alguns dos resultados mais expressivos que permitiram compreender sociologicamente os contornos teóricos e paradigmáticos da cultura organizacional em contexto educativo.

Esta primeira incursão empírica veio não só destacar o protagonismo da instituição escolar como contexto de investigação teórica e empírica ao nível dos estudos mais académicos (dissertaçôes de mestrado e doutoramento) sobre a cultura organizacional, como permitir concluir pela sua complexidade e potencialidade analítica. A fundamentação desta ideia central terá lugar no último ponto deste artigo, espaço dedicado à análise do movimento crítico da cultura organizacional e à sua particular expressão no campo educativo. A problematização teórica deste movimento será ilustrada pela referência a trabalhos de investigação concretos desenvolvidos no contexto da escola, pelo que (apenas nesta secção) optámos pela sua referenciação completa em nota de rodapé, de forma a 
Cultura organizacional escolar: apogeu investigativo no quadro de emergência...

permitir uma melhor explicitação e exemplificação da nossa argumentação. Neste caso concreto, julgamos não se justificar a duplicação desta informação bibliográfica no final do artigo.

A cultura organizacional escolar num contexto internacional de mudança económica, social e política

A conjuntura de crise económica que afectou significativamente o contexto da sociedade americana e alguns países europeus em meados da década de 1970, ao fazer abalar a crença no welfare state e no progresso ilimitado da economia, arrastou consigo um movimento de deslegitimação político-ideológica do sistema público de educação, cujos efeitos ao nível das políticas e reformas educativas ainda não deixaram de se fazer sentir, mesmo ao nível dos países mais periféricos. Com efeito, a perda de competitividade económica por parte dos Estados Unidos da América face ao mercado internacional, designadamente em relação ao Japão e outros países industrializados, surge intensamente associada ao declínio da qualidade da educação pública, bem expressa e divulgada pelo relatório $A$ nation at risk, provocando, como consequência mais expressiva, a necessidade de uma reforma educativa que fizesse frente à crise da educação. A crise económica, ao sugerir uma crise mais profunda no domínio da educação, transformou os problemas ligados à produtividade e eficácia económica em problemas ligados à produtividade e eficácia escolar, transpondo para este último contexto (as escolas) as mesmas lógicas, modelos, estratégias e paradigmas da gestão económico-empresarial (cf. entre outros, Apple, 1999, 2001, 2002; Ball, 2001; Whitty \& Power, 2002).

Face a este pano de fundo, a partir de finais da década de 1970, o sistema de educação pública é alvo privilegiado de algumas reformas, em grande parte sustentadas em valores mais próximos do modelo político-ideológico da emergente nova direita, desde então em ascensão tanto nos Estados Unidos da América como na Inglaterra. ${ }^{2}$ A ênfase nos valores democráticos e participativos, assim como nos processos de autonomização das escolas e dos professores, sob a égide de um Estado-providência com funções redistributivas, passa a ser substituída por valores de sentido contrário, tais como os valores da excelência, da competitividade, da eficácia, da livre escolha e do mercado, agora associados à defesa de um Estado fraco nos processos de responsabilização 
e regulação social (Apple, 1999). A este propósito, Afonso (1998, p. 96) sintetiza de forma esclarecedora a passagem dos anos de 1970 para a década de 80 , do ponto de vista dos valores que enfornaram as respectivas reformas educativas, salientando as tendências:

(...) da regulação para a desregulação; da escola pública para as escolhas educacionais e para a competição entre escolas; das preocupaçôes sociais para as preocupações com a economia e com a produtividade; da igualdade de oportunidades para a excelência; das necessidades educativas para as capacidades para a selectividade. (Grifos do autor)

De olhos postos na educação escolar, sector apontado como responsável em primeira mão pela crise económica, supostamente por ter falhado na produção de mão-de-obra suficientemente qualificada, adaptável e flexível às reais necessidades ditadas pelo mercado de trabalho, as forças políticas hegemónicas, ou, nas palavras de Apple (1999, p. 44), "a postura do guarda-chuva hegemónico vigente", passam a defender a reorganização das instituiçõos educativas à luz das necessidades estritamente económicas. E, deste modo, “(...) a educação converte-se num produto, tal como o pão ou os carros, e a única cultura que vale a pena abordar é a 'cultura empresarial' e as destrezas flexíveis, conhecimentos, disposições e valores, necessários para a competição económica” (Apple, 1999, p. 47; aspas do autor).

Para outros autores, assiste-se ao surgimento de um "novo paradigma de governo educacional”, a um "novo consenso" baseado "(...) numa concepção única de políticas para a competitividade económica, ou seja, o crescente abandono ou marginalização (não no que se refere à retórica) dos propósitos sociais da educação" (Ball, 2001, p. 100). Se bem que a hegemonia deste novo paradigma - que no relatório da OCDE (1995, p. 8), Governance in transition: public management reforms in $O E C D$ countries, apresenta-se sob a designação de "novo paradigma da gestão pública”, para fazer face às profundas mutaçôes em curso nas economias dos países membros desta organização multinacional, atendendo à eventual ineficácia das estruturas tradicionais da gestão pública - não afecte de forma determinista e homogénea todas as realidades sociais e educacionais, não deixa de constituir uma moldura político-ideológica omnipresente com fortes implicaçōes ao nível das políticas e práticas educacionais. Desde logo, ao analisar as implicaçôes deste "novo paradigma" proposto pela OCDE no campo educativo, Ball enuncia os três elementos- 
Cultura organizacional escolar: apogeu investigativo no quadro de emergência...

chave responsáveis pelas recentes transformações naquele campo: a forma do mercado, a gestão e a perfomatividade. ${ }^{3} \mathrm{~A}$ tranversalidade destes três imperativos às várias reformas educativas em curso em vários países, apesar das suas manifestações mais ou menos híbridas, multifacetadas e aditivas, denuncia processos multicomplexos de viragem e de transformação do domínio educativo. ${ }^{4}$

De acordo com vários estudos desenvolvidos sobre as políticas educativas no contexto das ideologias neoliberais e no quadro dos processos de globalização económico-cultural, ${ }^{5}$ podemos afirmar que uma das tendências mais generalizadas ao nível dos sistemas educativos se prende, em grande medida, com a sua progressiva mercadorização, associada às políticas de livre escolha, à privatização dos seus serviços, ao apelo da excelência escolar como valor supremo; mas, em sentido contrário, regista-se igualmente uma tendência para a recentralização da educação (Lima, 1995), cujos indicadores mais expressivos a reter são a expansão dos currículos nacionais, a imposição de exames nacionais e a implementação de esquemas de avaliação interna e externa das escolas. Estas tendências, ao constituirem "(...) partes de uma mesma equação (contraditória) que procura resolver a exigência simultânea de mais e menos Estado" (Afonso, 1998, p. 120), oriundas da convivência não pacífica entre ideologias neoconservadoras e ideologias de feição neoliberal, encontram como principal força motriz o pressuposto de que "organize-se a escola e tudo o resto se ordenará por arrastamento” (Apple, 1999, p. 36).

A exportação de todos os problemas económicos e sociais para o domínio da esfera educativa transformou a instituição escolar num contexto favorável à eclosão de reformas várias, em última instância, geradoras das mudanças desejadas. Das escolas espera-se não só o cumprimento das novas orientações centrais, como também a sua responsabilização pela procura das soluções mais eficazes para o seu desempenho. E, assim, ao relegar-se para um plano secundário, ou mesmo ao negar-se a centralidade dos valores democráticos e participativos, assiste-se à imposição de um único objectivo (fim) educacional, o da sua eficácia, competitividade e/ou perfomatividade. ${ }^{6}$

A crescente e redobrada pressão política, social e económica exercida sobre a instituição escolar, coagindo-a a adoptar modelos de administração e gestão tipicamente empresariais para poder dar conta das novas exigências ditadas pelo mercado de trabalho, arrastou consigo todo um movimento investigativo que passa a colocar no centro das 
suas prioridades teóricas o estudo das dimensões culturais da escola, fundamentalmente numa perspectiva gestionária e instrumental. Se bem que as dimensões culturais da escola tenham já constituido objecto de estudo na década de 1980 (como mais adiante demonstraremos), o certo é que o quadro político-axiológico emergente encetou o deslocamento dos interesses investigativos para as dimensões mais instrumentais, tecnicistas e pragmáticas da administração da educação.

Ao imputar-se ao sistema educativo a responsabilidade exclusiva pela fabricação de competências úteis, adaptáveis e mobilizáveis no mercado de trabalho, e ao sujeitá-lo a mecanismos de avaliação da sua eficácia, nomeadamente através dos exames nacionais e de esquemas centralizados de avaliação das escolas (com ou sem publicação de resultados), criam-se as condições ideais para infiltrar no mundo escolar as mesmas lógicas e valores que enformam o mundo económico. A produtividade de sucessos escolares pré-formatados a partir de perfis centralmente adoptados e globalmente definidos, ${ }^{7}$ traduzidos essencialmente por competências para competir, passa a constituir o mais importante indicador do grau de eficácia e excelência escolar que se deseja alcançar. Ao assemelhar-se a uma espécie de barómetro, esta medida (frequentemente traduzida por um número) personificará a qualidade do estabalecimento de ensino, a sua capacidade competitiva e funcional face aos ditames de uma economia globalizada. Neste seguimento, a cultura da escola, vista numa óptica de integração, de partilha, de comunhão dos objectivos e valores da organização, assume uma relevância significativa, na medida em que passa a ser vista como um mecanismo de estabilização social, fundamental para o alcance das metas desejadas. À semelhança do que se vai passando nos contextos empresariais, desenvolvem-se nos contextos escolares estudos sobre a cultura organizacional que visam ensaiar fórmulas de gestão da cultura, que garantam a efectiva concretização dos objectivos da eficácia e excelência escolar. E, assim, a cultura constitui-se como uma forte aliada das referidas ideologias políticas dominantes, especificamente nos países onde aquelas se manifestaram de uma forma mais acentuda. Por exemplo, como adiante veremos, é curioso verificar que os Estados Unidos da América e a Inglaterra, nos períodos de governação de R. Reagan e de M. Thatcher, foram os contextos onde mais se produziram trabalhos sobre a cultura organizacional das escolas, muito associados sobretudo à implementação das reformas educativas. 


\section{$\mathrm{O}$ apogeu investigativo das abordagens culturais na escola}

É na passagem da década de 1970 para a década de 1980 que Prosser (1999, p. 3) situa a emergência de um novo movimento centrado na modernização da escola ("school improvement"), ${ }^{8}$ responsável por um reincremento sem precedentes nos estudos sobre a cultura das organizaçōes escolares. O boom de produçôes que se verifica pós década de 1980 consagrará a problemática da cultura escolar na comunidade académica, sendo de destacar, no entanto, duas tendências dominantes: a indissociação da cultura escolar dos fenómenos da eficácia, da modernização e da mudança (Prosser, 1999, p. 7) e a profusão de uma grande diversidade de significados sobre a cultura escolar, produzidos ad hoc desde a década de 1970, daqui derivando uma consequente fragilidade teórica deste objecto de estudo.

A primeira tendência - já por nós identificada nas décadas de 1950 e 1960 - deve ser compreendida no quadro da nova conjuntura política e económica internacional que marcou o final do século XX, especialmente no que respeita à redefinição das orientações e das funçōes da instituição escolar. Submetida a novas lógicas e pressões políticas, económicas e sociais, a escola como organização tornou-se uma espécie de laboratório privilegiado de investigação, onde as dimensōes culturais assumiram, desde cedo, uma função de charneira nos processos de inovação e mudança escolares. A segunda tendência reflecte naturalmente a multiplicidade de olhares (teóricos, disciplinares e político-ideológicos) empreendidos sobre o objecto cultura, assim como os efeitos de transferência (acrítica) para os contextos educativos de quadros teóricos produzidos por referência à realidade empresarial.

Refém da nova conjuntura de mercado, a cultura escolar como problemática também não ficou imune ao impacto editorial alcançado por algumas publicações americanas sobre a cultura organizacional, designadamente as obras de Pascale e Athos (1984 [ed. orig. 1981]), Peters e Waterman (1987 [ed. orig. 1982]), ${ }^{9}$ Deal e Kennedy (1988), Kilmann et al. (1985), Ouchi (1986). Acompanhando o ritmo acelerado das publicaçôes, por vezes até rivalizando com os estudos empresariais, os trabalhos produzidos sobre a cultura organizacional em contextos escolares não atingiram, contudo, os índices de popularidade alcançados pelo sector empresarial, quer em termos comerciais (número de vendas), quer em termos de notoriedade e difusão teórica (número de vezes que o trabalho é citado). 
A partir dos dados (em bruto) fornecidos pela ISI Web of Science, relativamente ao universo dos trabalhos citados por cada autor incluído nesta base, construímos alguns rankings das publicaçôes e dos autores mais citados para melhor apreender os sentidos da evolução da problemática da cultura organizacional no contexto escolar. Ao analisarmos a Figura 1, relativa ao ranking das publicaçóes mais citadas, deparamo-nos com um cenário totalmente dominado pela literatura de tipo empresarial, o que denota a utilização prevalecente de um quadro de referência teórica inspirado na empresa e, porventura, reconvertido para outras realidades organizacionais.

Publicados, sobretudo, ao longo da década de 1980, os trabalhos sobre a cultura organizacional mais citados internacionalmente apresentam a tipologia de obra ou artigo científico (quase na mesma proporção), sendo de destacar, no entanto, que os três primeiros lugares são ocupados por obras americanas que ficaram celebrizadas neste domínio de estudo. ${ }^{10}$

\section{Figura 1}

Publicações mais citadas

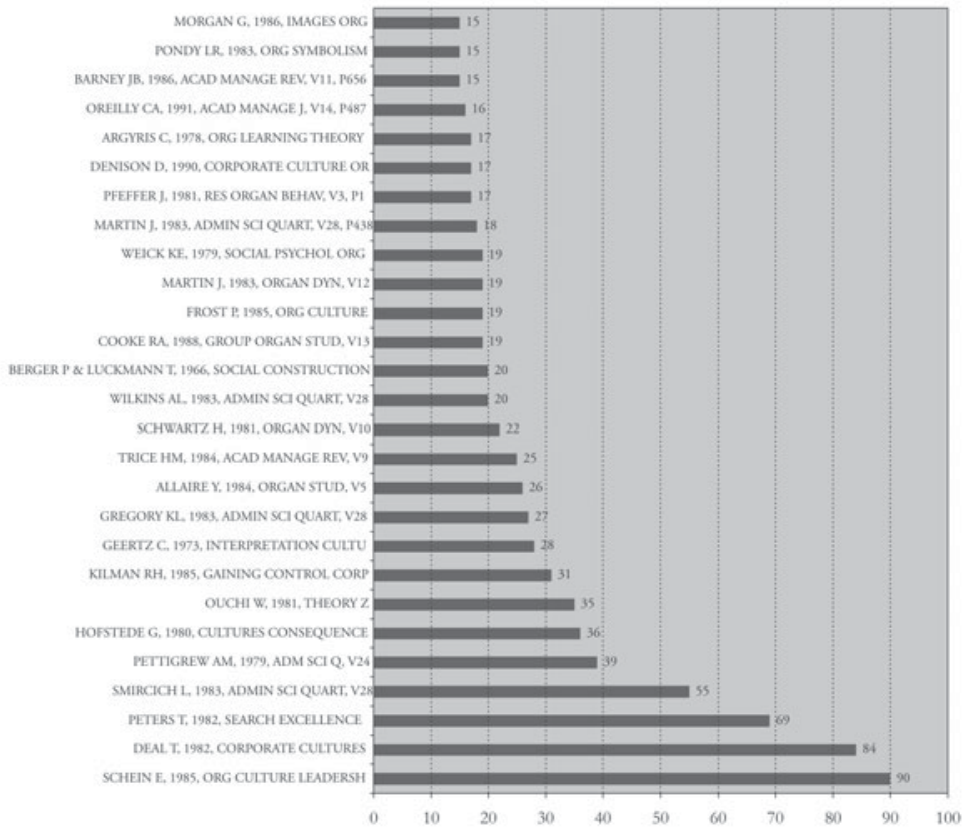

Educ. Soc., Campinas, vol. 28, n. 98, p. 151-179, jan./abr. 2007

Disponível em <http://www.cedes.unicamp.br> 
Não obstante o evidente protagonismo das áreas da gestão e da sociologia das organizaçôes, ${ }^{11}$ a pluralidade de posicionamentos teóricos, metodológicos e epistemológicos implícita neste ranking revela bem a complexidade inerente ao processo de construção da problemática da cultura organizacional. Por um lado, e ocupando os lugares cimeiros, encontramse trabalhos teoricamente inscritos numa perspectiva integradora da cultura, mais próxima de registos normativos e gestionários que privilegiam os processos de mudança organizacional; por outro lado, e numa proporção não desprezível, ressaltam os trabalhos que adoptam um enfoque fundamentalmente crítico e problematizador, mais próximos de perspectivas diferenciadoras e fragmentadoras da cultura (por exemplo, Smircich (1983); Pettigrew (1979); Allaire e Firsouritu (1984); Berger e Luckmann (1990); Martin et al. (1983, 1988), Martin (1992, 2002), Alvesson (2002), entre outras referências.

Se bem que o primeiro enfoque, ocupado pelos lugares cimeiros do ranking, apareça em vantagem competitiva, julgamos, no entanto, que outros trabalhos de sentido teórico inverso, quer em termos de representatividade estatística, quer em relação aos lugares ocupados, rivalizam e relativizam a hegemonia do paradigma funcionalista na análise da cultura organizacional. Esta tese ganha consistência quando confrontamos estas informações com os dados evidenciados pelo ranking relativo aos autores mais citados (Figura 2), onde, à excepção do destacado E. Schein, é possível encontrar autores de distintas filiações teóricas em lugares de significativa difusão.

\section{Figura 2}

Autores mais citados (ISI)

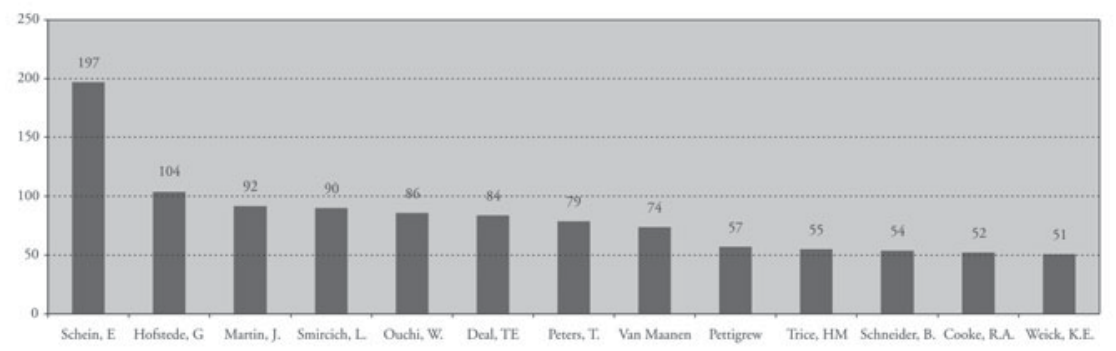


Se é evidente que Edgar Schein se tornou numa espécie de guru da cultura organizacional (figurando no primeiro lugar nos dois rankings, ora como obra, ora como autor incontestavelmente mais citado), ${ }^{12}$ não deixa de ser pertinente verificar que duas das autoras mais importantes no âmbito do paradigma crítico ocupam o terceiro (Linda Smircich) e o quarto lugar (Joanne Martin). Objecto de distintas e antagónicas focalizaçôes teóricas e epistemológicas, assim como de diferentes enfoques metodológicos por nós já amplamente discutidos em anteriores trabalhos (cf. Torres, 1997, 2001, 2004), a cultura organizacional tem vindo a construir-se como uma problemática de natureza multidisciplinar e multiparadigmática, espelhando bem as influências teóricas, políticas e ideológicas plurais a que tem sido sujeita. Os dados estatísticos que aqui apresentamos têm o condão de ilustrar empiricamente a natureza multiforme deste tema, ao revelar a coexistência de distintos e antagónicos contextos de produção (dos mais eminentemente académicos aos de índole mais gestionária e técnica), orientados por lógicas de produção, de divulgação e de consumo igualmente díspares e por vezes desconexas.

Em relação à esfera educativa, é notória a sua similitude com o quadro de fundo que acabamos de traçar. Se os trabalhos sobre a cultura organizacional em contexto escolar não figuram entre os mais citados (logo, entre os mais lidos, divulgados e, consequentemente, aprofundados), é lógico pensarmos que o processo de construção teórica que lhes subjaz poderá estar sujeito às pressôes de um corpus teórico já academicamente instituído. Sobretudo quando detectamos que, entre as duas dezenas de trabalhos que figuram nos rankings, apenas conseguimos identificar dois autores que têm reflectido sobre a área da educação, concretamente Terrence Deal e Karl Weick, mesmo que os seus trabalhos mais conhecidos não incidam sobre a cultura organizacional da escola. ${ }^{13}$ Mesmo assim, ambos os trabalhos, ao instituirem-se como matrizes de referência teórica das abordagens organizacionais da escola, marcarão de forma indelével a construção da problemática da cultura escolar, não sendo alheio a este fenómeno o facto de simbolizarem dois paradigmas teóricos distintos na perspectivação deste tema: Deal e Kennedy, inscritos num paradigma mais funcionalista, protagonizam uma leitura integradora e gestionária da cultura; Karl Weick, influenciado por um paradigma mais interpretativo e crítico, defende e inaugura um enfoque cultural mais de natureza fragmentadora.

$\mathrm{Na}$ tentativa de apreender o sentido evolutivo desta problemática, especificamente no contexto escolar, confrontámos as quatro bases 
de dados internacionais e elaborámos um gráfico com dados comparativos (cf. Figura 3) que nos permitiu identificar o lugar e o estatuto que o sistema educativo tem ocupado como campo investigativo ao longo das últimas décadas. Uma vez mais confirmamos a ideia de uma evolução vertiginosa, do ponto de vista quantitativo, ao longo da década de 1990, sendo de destacar o lugar cimeiro e pioneiro ocupado pela instituição escolar no contexto de produção mais académico (UMI)..$^{14}$ Uma análise mais aprofundada aos conteúdos destes trabalhos produzidos por referência ao contexto escolar permitiu-nos identificar dois movimentos investigativos de natureza teórica e metodológica distinta: o movimento integrador, de origem predominantemente anglo-saxónica e de registo mais pragmático e gestionário, dominado pelas metodologias quantitativas e, em contra-corrente, o movimento crítico, com maior afirmação na Europa e de registo mais críticoreflexivo, orientado pelas metodologias qualitativas.

\section{Figura 3}

Evolução comparativa dos estudos sobre a cultura organizacional

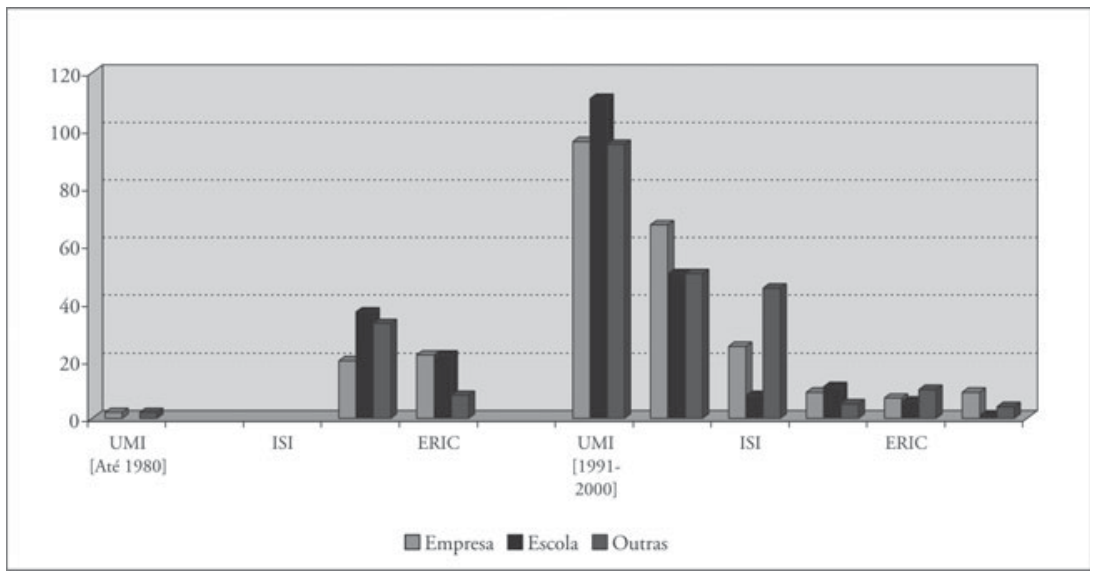

O desenvolvimento do movimento crítico na análise da cultura organizacional em contexto escolar

Em paralelo com a expansão de âmbito internacional do movimento integrador, mais preocupado com os usos técnico-gestionários da cul- 
tura, assiste-se ao despontar de um outro, mais crítico e problematizador da cultura organizacional, sendo de destacar a sua crescente afirmação no domínio específico da educação, desde a última década do século XX. Os contextos escolares, tanto ao nível do básico e secundário como ao nível superior, ao mesmo tempo que se tornaram em objectos privilegiados de investigação numa óptica mais funcionalista e gestionária, suscitaram em simultâneo o desenvolvimento de diversas propostas que permitiram análises mais críticas e holísticas dos fenómenos culturais.

Se bem que este movimento alternativo não represente um corpus teórico-científico homogéneo e uniforme, dadas as múltiplas filiações teóricas e ideológicas que encerra, é possível, mesmo assim, identificar um denominador comum que atravessa a maioria dos trabalhos integrados nesta linha de investigação. Esta matriz que intercepta os vários trabalhos assenta na rejeição de uma imagem exclusivamente integradora e uniforme de cultura, propondo, em contrapartida, a análise e interpretação de várias possibilidades de manifestações culturais. $\mathrm{O}$ desvelamento da natureza multiforme e desigual da cultura das escolas, apesar de constituir o móbil comum destas investigações, não deixa de contemplar distintos objectivos e diferenciadas posturas face ao objecto em causa. O questionamento, sob diferentes ângulos de análise, dos estudos de tipo monocultural permitiu não só um alargamento teórico-científico da problemática, como visibilizou distintas e contraditórias modalidades de apreensão da cultura organizacional da escola.

A primeira modalidade, menos expressiva em termos estatísticos e de pendor também menos crítico, é representada pelos trabalhos que, apesar de partirem de uma perspectiva diferenciadora de cultura, persistem numa agenda político-ideológica não muito distante daquela que caracteriza o movimento integrador. Muda o paradigma teórico mas mantém-se, quase na originalidade, a agenda política. Isto é, parte-se do diagnóstico das subculturas escolares, recorrendo-se a tipologias várias, com o objectivo de identificar se a cultura dominante num determinado contexto corresponde ao ideal-tipo considerado mais ajustado ao alcance da eficácia, da performatividade e da excelência. ${ }^{15} \mathrm{O}$ processo de identificação destas subculturas torna-se importante tanto como instrumento prévio e anterior à preparação das reformas educativas, ${ }^{16}$ como mecanismo de gestão e regulação à posteriori das mesmas, investindo-se neste caso na mudança da subcultura dominante. ${ }^{17}$ 
Diante do exposto, os trabalhos que inscrevemos nesta categoria não deixam ainda de reflectir algumas das tensões típicas das aborgagens tecnicistas, não obstante o seu potencial teórico sugira já uma certa desvinculação dos paradigmas mais funcionalistas. Ao considerar-se a cultura como uma variável dependente e interna às fronteiras físicas da escola e de existência certa e diagnosticável, não se elege como objecto de análise a indagação dos processos que intervêm na sua construção. Persiste, então, um registo ainda muito descritivo e de natureza confirmatória, centrado na comprovação empírica da coexistência de múltiplas subculturas no contexto escolar e, correlativamente, no diagnóstico dos traços identificativos da subcultura dominante. Subjacente à adopção de tipologias clássicas para o diagnóstico dos tipos culturais da escola, reside a crença no pressuposto de que, independentemente das especificidades estruturais e culturais da escola, quanto mais os resultados da investigação confirmarem a hegemonia de um certo ideal-tipo cultural, maiores seriam as possibilidades de se alcançar a eficácia ao nível da gestão e administração escolares. ${ }^{18}$

A segunda modalidade de apreensão da cultura organizacional da escola distingue-se da anterior, sobretudo, pela consideração dos factores externos à escola no desenvolvimento das subculturas escolares. Embora pouco relevantes numericamente, os trabalhos conhecidos no âmbito desta modalidade não deixam dúvidas relativamente ao papel secundário atribuído às variáveis de contingência externa na construção da cultura organizacional da escola. E entre os factores externos eleitos como potencialmente importantes para o entendimento da cultura escolar, figuram os factores ligados ao meio sócio-económico-cultural em que a escola está inserida ${ }^{19}$ e os factores relacionados com a etnia, nomeadamente, as culturas afro-americanas e latino-americanas. ${ }^{20}$ Ao privilegiar-se analiticamente os factores externos à escola na sobredeterminação da cultura organizacional, no caso em apreço, na formação de subculturas escolares, tende-se a incorrer nalguns impasses típicos das abordagens contingenciais. Desde logo, a não contemplação dos factores internos à organização escolar na construção da cultura pressupõe um desvio analítico do interior para o exterior da escola, o qual parece comprometer o carácter holístico e interfactorial inerente a esta problemática. O estatuto ontológico da cultura organizacional da escola parece sofrer uma viragem, na medida em que a sua configuração passa a estar subjugada às ordens externas, sem que, entretanto, se 
consiga superar a tensão, a nosso ver crucial, entre o formal (estrutura) e o informal (acção). As esferas da acção organizacional, reportadas às dinâmicas dos professores, alunos, funcionários continuam a ser perspectivadas como se de entidades passivas e acríticas se tratassem, apenas reagindo sem resistência aos estímulos provenientes do exterior.

Neste seguimento, julgamos mesmo estar diante de uma situação paradoxal marcada por duas tendências de sentido inverso: uma abertura política da escola ao meio e, em sentido contrário, um fechamento do seu campo analítico. Por um lado, assistimos no plano internacional à difusão de orientações educativas voltadas para o mercado, onde a imposição de lógicas economicistas impera, obrigando assim a que a escola não só promova uma maior abertura à comunidade, como passe a ficar sua refém..$^{21}$ Por outro lado, o balanço das investigações realizadas no domínio da cultura organizacional em contexto escolar faz sobressair a supremacia de linhas teóricas que primam por análises centradas nos processos internos das escolas, hiperbolizando, nalguns casos, a relevância destas ordens internas (a liderança, por exemplo) na criação de culturas escolares excelentes e performantes. Tal cenário parece indiciar, em nossa opinião, a presença de uma estratégia reguladora por parte das instituições de ensino, que, ao mesmo tempo que são coagidas a desenvolver processos de adaptação externa, promovem, como mecanismo de defesa e sobrevivência, políticas de integração interna.

Obviamente que a agenda que acabamos de enunciar remete para um registo mais teórico, reflexivo e crítico, exigindo, por isso, uma inflexão analítica, dificilmente articulável com a agenda de cariz mais ideológico e político que condicionou grande parte das abordagens sobre a cultura organizacional das escolas. É num contexto marcado por prioridades mais heurísticas do que políticas, onde a lógica da compreensão e interpretação sociológica se sobrepõe à lógica da produção rápida de resultados estatisticamente validados, que se desenvolve a terceira e última modalidade de apreensão da cultura escolar, no âmbito do movimento crítico.

Celebrizando o registo mais crítico e problematizador de entre as três modalidades de apreensão da cultura incluídas no movimento crítico, os vários trabalhos produzidos no âmbito desta agenda investigativa constituem já um suporte teórico e científico relativamente sustentado, sobretudo quando comparado com a fragilidade verificada no campo em- 
Cultura organizacional escolar: apogeu investigativo no quadro de emergência...

presarial, por exemplo. De facto, ao constatarmos que o contexto da educação escolar tem sido aquele que mais tem fomentado o aprofundamento teórico deste movimento, quer ao nível das instâncias do ensino superior, quer ao nível do ensino básico e secundário, somos tentados a admitir a hipótese de existência de uma correlação entre as especificidades da estrutura-acção da escola e os seus efeitos ao nível da construção da cultura organizacional. Isto é, as singularidades políticas e organizacionais da escola, ao alicerçarem-se sob diferentes "planos analíticos"22 com impacto assinalável ao nível das práticas e interacções quotidianas, parecem exigir a convocação de modelos de análise alternativos, susceptíveis de melhor apreender o carácter holístico e multifactorial que subjaz ao "processo de construção e reconstrução da cultura da escola" (cf. Bates, 1987, p. 88-89; Sparkes \& Bloomer, 1993, p. 171).

Decorrente das especificidades do modelo organizativo da escola, o impacto das reformas educativas sobre os processos de mudança nas organizações escolares assume proporções mais expressivas, ao visibilizar uma descontinuidade entre o contexto heterónimo de concepção de orientações/medidas (administração central) e o contexto localizado e periférico de adopção e implementação pelos actores (escolas). A constatação de uma certa desregulação e, por vezes mesmo, de uma ruptura profunda entre as esferas da concepção (objectivos) e os espaços concretos de implementação (resultados) fomentou a necessidade de se compreender, por um lado, as especificidades culturais dos contextos onde decorre a acção educativa e, por outro, a reacção destes a um conjunto de factores, como, por exemplo, um pacote de programas de acção externamente produzidos. ${ }^{23}$ Esta dupla preocupação em olhar a cultura organizacional simultâneamente como processo e produto parece estar presente em grande parte das investigações enquadradas no movimento crítico. ${ }^{24}$

Se bem que a resistência à dissociação das ideias de cultura organizacional e desenvolvimento da escola continue presente nalguns trabalhos, ${ }^{25}$ privilegia-se, doravante, neste movimento, um enfoque multidisciplinar, susceptível de desocultar os factores intervenientes na construção da cultura organizacional da escola, podendo esta traduzir-se em distintas manifestações consoante o jogo de forças coexistentes em determinado contexto. Por isso, investe-se em abordagens mais holísticas, que extravasam os limites físicos da própria organização, ora enfatizando os processos de construção cultural de cima para baixo (top-down), ${ }^{26}$ ora 
questionando tal orientação, proclamando antes uma inflexão analítica, assente numa recentralização da escola como espaço investigativo, deslocando o enfoque de baixo para cima (down-top). ${ }^{27}$

Ao procurar-se um quadro explicativo para os processos de construção e reconstrução da cultura organizacional da escola, sucederam-se investigaçōes várias que procuravam evidenciar o cáracter interactivo entre as diversas variáveis em jogo, umas mais internas à organização, outras de cariz mais exógeno à escola, explorando agora os contextos da acção concreta, os processos de negociação entre os actores, os palcos onde decorrem os conflitos, enfim, os domínios onde a construção do simbólico tem lugar. ${ }^{28}$

E, neste seguimento, os professores, os alunos e os pais, como protagonistas da acção educativa, tornaram-se nos actores mais investigados, enquanto potenciais representantes e competidores de distintas subculturas. ${ }^{29}$ Tomados como agentes pró-activos na construção e reconstrução da cultura organizacional da escola, as dinâmicas de interacção entre professores e alunos passam a ser exploradas de um duplo ponto de vista: como reflexos de uma estrutura escolar institucionalizada para a conformidade e convergência (normativa, ideológica, cultural), mas, em simultâneo, como denunciadoras de uma anti-estrutura de resistência, ${ }^{30}$ resultante de um complexo jogo de influências internas e externas à organização escolar. O desafio em questão será o de desvendar o complexo processo de produção e reprodução dos sistemas culturais nas e pelas escolas, partindo do pressuposto de que a institução escolar poderá constituir apenas um espaço de mediação cultural entre a cultura societal e a cultura organizacional projectada. Ou, nas palavras de Pérez Gomez (1998, p. 12), a escola deveria ser entendida como um cruzamento de culturas, “(...) que provocan tensiones, aperturas, restricciones y contrastes en la construcción de significados".

A natureza multidisciplinar deste movimento, assim como a sua associação a metodologias de investigação mais qualitativas, não só permitiu uma abordagem mais aprofundada e consolidada sobre a problemática da cultura em contexto escolar, como correlativamente desmistificou algumas apropriaçôes ideológicas e políticas a que aquela tem sido sujeita. Ao denunciar-se a presença de diferenciadas manifestações culturais (cultura integradora, diferenciadora e/ou fragmentadora) 
Cultura organizacional escolar: apogeu investigativo no quadro de emergência...

num mesmo contexto escolar, ${ }^{31}$ resultante de um jogo dialéctico de forças internas e externas à escola, questiona-se, como consequência, a natureza positivista (fixista e estática) dos pressupostos integradores da cultura, assim como a sua relação directa com a eficácia e a eficiência escolares.

Inscrito no seio de um paradigma construtivista, este movimento está ainda longe de atingir a sua maturidade científica. Não obstante a diversidade de trabalhos produzidos em diferentes contextos escolares, julgamos, contudo, que a edificação de um modelo teórico para a análise da cultura organizacional da escola ainda se encontra comprometida pelo tradicional fechamento disciplinar dos estudos e pelos limites temporais e lógicas institucionalmente impostas aos projectos de investigação. Ou seja, as investigaçôes desenvolvidas sobre este objecto de estudo resultam, na maioria de casos, da realização de dissertações de mestrado e doutoramento, limitadas no tempo e no espaço, não havendo registo de projectos colectivos de longa duração, que permitissem a consolidação científica de uma matriz teórica especificamente inspirada na realidade escolar.

\section{Recebido em fevereiro de 2006 e aprovado em setembro de 2006.}

\section{Notas}

1. A este propósito, Deal (1988), um dos autores que se consagrou no estudo da cultura organizacional das escolas, defende a tese de que o estudo desta problemática terá sido estimulado, no início, pelas investigaçóes nas organizaçóes escolares. Por exemplo, os estudos desenvolvidos na década de 1970 por Meyer e Scott (1992 [ed. orig. 1977]) sobre as estruturas formais perspectivadas a partir do seu carácter ritual e cerimonial representam bem o interesse investigativo pelas dimensôes simbólicas das escolas, num registo reflexivo e interpretativo, ainda desmarcado de eventuais preocupaçōes gestionárias. Registese ainda, na mesma década, os trabalhos desenvolvidos por Cohen et al. (1979) e por Meyer e Rowan (1977).

2. Para uma compreensão sociológica do processo de desenvolvimento e consolidação da ofensiva neoliberal britânica, protagonizada por instituições privadas de investigação com fortes influências no plano internacional, nomeadamente na divulgação dos temas da privatização, da desregulamentação e da precarização do trabalho, consultar o trabalho de Dixon (1999) com o sugestivo título Os evangelistas do mercado.

3. Num trabalho recente, Michel St-Germain analisa as consequências da nova gestão pública sobre as reformas educativas no contexto internacional, com especial destaque para a realidade do Canadá, avançando como principal argumento a emergência do pensamento contábil em educação, cujos princípios se resumem ao crescimento da participação decisional dos clientes vistos como consumidores e eleitores, à obrigatoriedade dos resul- 
tados quantificáveis, à descentralização, à imputabilidade acrescida, à implementação de padrões de controlo. Cf. St-Germain (2001).

4. Num capítulo de livro escrito por Cibulka (1999), intitulado Ideological lenses for interpreting political and economic changes affecting schooling, é debatido e aprofundado, a partir de diferentes prismas ideológicos, o fenómeno de mudança política e económica e suas multiformes repercussōes ao nível do sistema educativo. Igualmente pertinente, o capítulo escrito por Reyes e outros (1999) (publicado na mesma obra que o anterior), corrobora a natureza exigente, dificultosa e laboriosa subjacente a esta problemática, destacando a centralidade das forças externas ("Delta Forces") na reestruturação da educação, designadamente, na difusão do modelo neo-corporativo de escola, assente na competitividade, hierarquia, disciplina, segregação. O autor debruça-se, ainda, sobre os perigos de secundarização do valor equidade educativa num contexto fortemente marcado pela competitividade, qualidade e excelência.

5. Sobre a complexa relação entre globalização e educação, Roger Dale tem adoptado no seu trabalho duas abordagens que diferem nas suas propostas explicativas, nomeadamente em relação à força do efeito extra e supranacional sobre o campo educativo: a primeira, designada de "Cultura Educacional Mundial Comum", da autoria de Meyer e colegas, e a segunda, desenvolvida pelo próprio autor e intitulada "Agenda Globalmente Estruturada para a Educação". Se bem que o objectivo central nesta secção deste capítulo não passe pela análise privilegiada destes dois fenómenos (globalização e educação), contudo, não nos furtaremos a assinalar, sempre que possível, alguns trabalhos que possam contribuir para a compreensão dos alicerces teóricos da análise das dimensōes culturais das escolas. Cf. Dale (2001).

6. Entre outros autores que têm reflectido sobre o impacto das ideologias da modernização, de feição neoliberal sobre a democratização das instituições educativas, apoiamo-nos nos trabalhos desenvolvidos por Apple (1999), Ball (2001). Em Portugal, consultar Lima (1994), Stoer; Cortesão (1999a e 1999b), Afonso (1998, 2000), Estêvão (1998; 2002) e Antunes (2004).

7. Referimo-nos, fundamentalmente, à importância das decisóes políticas tomadas no quadro da União Europeia e as suas repercussōes a nível nacional. Quanto à definição das competências básicas e dos perfis profissionais, são significativas as conclusões saídas do Conselho Europeu de Lisboa, 23-24 de março de 2000, nomeadamente as que foram produzidas pela Presidência Portuguesa. Consultar Rodrigues (2000), sobretudo no anexo II, o ponto 25, intitulado "Educação e formação para a vida e o trabalho na sociedade do conhecimento” (p. 224-225).

8. Para uma análise mais aprofundada e crítica deste movimento, sugerimos, entre outros trabalhos, os capítulos de livros produzidos por Louis et al. (1999), intitulado Rethinking school improvement, e por Ouston (1999), com o título School effectiveness and school improvement: critique of a movement.

9. Já em pleno século XXI, a editora Bloomsbury Publishing interrogou mais de 3 mil homens e mulheres de negócios de todo o mundo sobre "Quais as suas mais importantes referências literárias em gestão?”. Dos 20 essenciais que se “(...) deve consultar para superar desafios, estabelecer metas e alcançar objectivos", figura, em primeiro lugar, a obra de maior sucesso na dédaca de 1980, In serach of excellence, de Peters \& Waterman. Este bestseller abriu um duplo caminho: ao mercado de vendas de livros de gestão e negócios e fomentou, por outro lado, o estudo da cultura organizacional, essencialmente numa perspectiva gestionária. Cf. Os melhores livros (de Gestão...) de sempre, Executive Digest, n. 100, p. 52-58, fev. 2003.

Educ. Soc., Campinas, vol. 28, n. 98, p. 151-179, jan./abr. 2007

Disponível em <http://www.cedes.unicamp.br> 
10. A acrescer a esta informação, a análise do cruzamento entre as variáveis número de vezes que o trabalho foi citado e país de residência dos autores, relativas aos dados totais constantes na ISI, aponta para uma relação directa entre aquelas variáveis, isto é, os trabalhos sobre a cultura organizacional mais citados pela comunidade científica são tendencialmente produzidos por autores americanos. No entanto, na categoria que agrega os trabalhos citados entre 10 a 50 vezes, se juntarmos os autores residentes na Europa com todos os outros com residência fora da Europa, conseguimos obter valores próximos dos atingidos pelos autores americanos, o que poderá indiciar a existência de um conjunto de trabalhos sobre a cultura organizacional produzidos fora do contexto americano, que, apesar de não ter atingido elevados indíces de divulgação, não deixam de representar um contingente teórico e científico com alguma expressão a nível internacional.

11. De forma similar, os dados totais da ISI comprovam igualmente a hegemonia dos domínios da gestão e administração no enquadramento disciplinar dos trabalhos mais citados. $\mathrm{O}$ cruzamento entre as variáveis número de vezes que o trabalho foi citado e área científica da publicação é revelador da centralidade que aquela área científica e disciplinar representa no desenvolvimento de trabalhos sobre a cultura organizacional. De salientar que a área da Educação apresenta valores pouco significativos, mais baixos do que as áreas da Saúde e Psicologia.

12. De facto, os valores alcançados por Edgar Schein distanciam-se significativamente dos demais autores, se compararmos o número de vezes que ele foi citado (197) com o número médio de vezes que os 158 trabalhos conseguiram reunir - 16 vezes. Refira-se também que num total de 285 trabalhos seriado na ISI, verificamos que 127 nunca foram alvo de qualquer citação.

13. De facto, apesar de Terrence Deal ter vindo a produzir importantes trabalhos na área da educação desde a década de 1970, de que são exemplo alguns estudos individuais (1975, $1982,1985,1988)$ e em co-autoria $(1977,1983$ - vários), foi com a obra publicada em 1982, em parceria com Allen Kennedy com o título Corporate culture. The rites and rituals of corporate life, que o autor se tornou conhecido e divulgado na comunidade científica. Representando esta obra uma espécie de manual teórico e prático para o estudo da cultura organizacional, sobretudo inspirado nas organizaçóes empresariais, o autor prossegue nos anos seguintes com o estudo desta problemática, transferindo aquele quadro teórico (de índole gestionária) para a análise dos fenómenos culturais da escola, sobretudo numa perspectiva de inovação e mudança. Por sua vez, Karl Weick, um autor que desde a década de 1970 tem vindo a dedicar-se ao estudo da escola, também figura como um dos autores mais citados, designadamente a sua obra publicada em 1969 e intitulada A psicologia social da organização, que se instituiu como uma capital referência teórica para o estudo da cultura organizacional. Como já tivemos oportunidade de salientar, este autor dedicou-se nos anos seguintes ao estudo das organizaçóes escolares, tendo mesmo eleito a cultura escolar como uma das dimensões de análise.

14. Note-se que, de entre as quatro bases electrónicas consultadas, a UMI é a única que integra exclusivamente dissertaçôes de doutoramento e de mestrado. Todas as outras bases integram uma grande multiplicidade de trabalhos: livros, capítulos de livros, artigos científicos, comunicações em actas, resumos e recensões críticas de trabalhos, entre outros.

15. A tipologia cultural mais utilizada nestes estudos é a de Cameron e Ettington (1988), que prevê a ocorrência de quatro tipos culturais: clā, adhocracia, hierarquia e mercado. Também no que concerne à base de dados UMI, encontramos trabalhos que adoptaram esta proposta tipológica, de onde se destacam: uma dissertação de doutoramento realizada por Berrio (1999): Organizational culture and organizational learning in public, non-profit institu- 
tions: a profile of Ohio State University Extension. The Ohio State University. PhD, 149 p. (UMI); duas dissertações de mestrado recentemente realizadas por Poppens (2000): Perceived and preferred organizational culture types and organizational commitment at Midwestern Private Nonprofit Colleges. University of South Dakota. EDD, 138p. (UMI); e por McGalliard (2001): The organizational culture of women's colleges: a multiple-case study. The Florida State University. EDD, 127p. (UMI).

16. Cf., por exemplo, a dissertação de doutoramento desenvolvida por Babione (1995) - A case study of the interaction between organizational culture and processes of continuous quality improvement in the community college environment, The University of Toledo. $\mathrm{PhD}, 223 \mathrm{p}$. (UMI) -, onde o autor propõe um estudo aprofundado das subculturas escolares, fundado no pressuposto de que o sucesso da implementação dos programas/reformas educacionais está dependente da natureza e do grau de expressão assumida pelas diversas subculturas escolares. Na mesma linha de análise, a dissertação desenvolvida por Ferrell (1996) Teacher attendance, organizational culture, and occupational culture: a qualitative study (ERIC) - propõe uma análise das subculturas escolares, em particular da cultura ocupacional docente, passível de auxiliar a concepção de políticas e programas de combate às elevadas taxas de absentismo dos professores nos Estados Unidos da América.

17. A título ilustrativo, registamos duas dissertações produzidas no mesmo ano: a primeira, de doutoramento, de Byrne (1995) - Experiencing paradise, living in a paradox: a cultural study of an academic department. The University of Nebraska (Lincolm). PhD, 161p. (UMI); a segunda, de mestrado, de Riddle (1995) - Organizational culture and reestructuring: a case studdy of Journalism Department reorganization. Northern Arizona University. EDD, 425p. (UMI).

18. Admite-se e proclama-se, igualmente, a possibilidade de gerir as várias subculturas escolares a partir de processos de liderança eficazes e eficientes. Nestes casos, a agenda que subjaz a algumas abordagens apenas se torna distinguível da do movimento integrador pelo facto de admitir a diferenciação cultural. Por exemplo, a obra produzida por Sergiovanni e Carver, e editada em 1973, com o título O novo executivo escolar: uma teoria de administração, representa bem o alcance deste enfoque, ao procurar criar uma ciência administrativa aplicada à educação e, designadamente, ao propôr uma decisão de valor - "um padrão de crenças para a orientação da decisão educacional" (p. 37) - assente num modelo de eficiência administrativa que pressupõe a gestão da diversidade e conflitualidade cultural. Como já tivemos oportunidade de registar, o primeiro autor, duas décadas mais tarde, produz a obra Building community in schools, onde aprofunda a ideia de que "Community building is the secret weapon that can help domesticate the wild cultures that now seem so omnipresent in our schools" (Sergiovanni, 1994, xiv).

19. Cf., por exemplo, a dissertação de doutoramento realizada por Davilla (1995) - Organizational culture in a Mexican high school: a case study. The Pennsylvania State University. $\mathrm{PhD}$, 374p. (UMI) ,- onde a autora analisa a importância do factor religioso no desenvolvimento da cultura organizacional de uma escola mexicana (comparando as especificidades desta com a americana); a dissertação de mestrado de Bowles (2000) - The impact of school organizational culture on the academic achievement of elementary students. South Carolina State University. EDD, 74p. (UMI) -, onde se reafirma a importância do meio sócioeconómico (baixo, médio e alto) no desenvolvimento de diferentes culturas de escola e, consequentemente, do desempenho escolar dos alunos. De âmbito mais geral, registamos ainda um paper apresentado por Seagren et al. (1990) - The implications and opportunities for principal practices and preparation programs based on a comparative study of organizational culture in selected schools in Australia and the USA - no Annual Meeting of

Educ. Soc., Campinas, vol. 28, n. 98, p. 151-179, jan./abr. 2007

Disponível em <http://www.cedes.unicamp.br> 
the National Council of Professors of Educational Administration, Los Angeles, 12-17 agosto (ERIC), onde se analisa a influência da cultura societal sobre a cultura organizacional de várias escolas americanas e australianas.

20. Diversas investigações americanas elegeram como objecto de estudo a relação entre a etnicidade e a configuração da cultura organizacional em contexto escolar, no sentido de indagarem as (distintas) percepções sobre as práticas de incorporação/rejeição de diferentes grupos étnicos (brancos, latino-americanos e afro-americanos) no contexto de trabalho escolar e suas consequências ao nível da (re)formulação da cultura organizacional das escolas públicas americanas. Cf., entre outros, as dissertações de doutoramento realizadas por Goodloe (1995) - The influence of assimilation and retention practices within school organizational culture on African-American certified employees in public education. University of Colorado at Denver Graduate School of Public Affairs. PhD, 229p. (UMI) e Benavidez (1995) - The influence of assimilation and retention practices within school organizational culture on Latino-American certified employees in public education. University of Colorado at Denver Graduate School of Public Affairs. PhD, 225p. (UmI).

21. Paradigmática da importância crescente dos factores externos ao nível do funcionamento das escolas, a obra editada por Foskett (1992), intitulada Managing external relations in schools, apresenta um conjunto de análises centradas nas diversas esferas que o exterior pode comportar: o contexto educativo/institucional, a comunidade (pais, media, indústria e empregadores, meio envolvente), o contexto do mercado.

22. Referimo-nos, na esteira de Licínio Lima, ao "plano das orientações para a acção" e ao "plano da acção organizacional", regidos por distintas regras e lógicas organizacionais. Para uma análise mais aprofundada do modelo teórico construído por este autor, consultar Lima (1992).

23. É nesta linha de argumentação que podemos enquadrar o recente trabalho de Lúcia Teixeira (2001), intitulado A cultura organizacional e o impacto das propostas de mudança em escolas estaduais de Minas Gerais, onde a autora questiona o impacto de propostas de mudança centralmente concebidas sobre o funcionamento de escolas com especificidades culturais e identitárias distintas. Igualmente elucidativo, Elmore (1987) reflecte a propósito das relações entre o plano da concepção da reforma educativa, externamente localizado, e o plano da "ordem normativa" (cultura de escola), organizacionalmente construído, procurando analisar e explicar as razóes da resistência dos professores à reforma, por referência à especificidade da "cultura de autoridade" desenvolvida nas escolas.

24. Entre um vasto conjunto de trabalhos referenciáveis no âmbito desta linha, destacamos a dissertação de mestrado produzida por Wood (1998), Organizational culture and leadership at Berea College: an historical inquiry into saga development and underlying assumptions. West Virginia University. EDD, 314p. (UMI), onde o autor explicita o seu ponto de partida no resumo da dissertação: "Culture within an organization is both process and product. It is both a dynamic agent of influence within the temporal and spatial context of organizational life and an object of study approached from the actor's point of view and thickly described". Assumindo, de forma igualmente explícita, o mesmo ponto de partida, a dissertação de mestrado defendida no Canadá por Lewis (1997), Shifting bodies: a study of culture in an Ontario secondary school. Queen's University at Kingston (Canadá). MED, 168p. (UMI), elege como objectivo compreender "(...) the way the school works. I pursue my purpose in an attempt to find out how power and knowledge serve to maintain the institution of the school and how my place in the school affects my own thinking".

25. Por exemplo, na dissertação de mestrado desenvolvida por Baluss (1995) - The spirit of innovation and the soul of tradition: institutional advancement and organizational culture at Oxford University College. Peabody College for Teachers of Vanderbilt University. EDD, 
506p. (UMI) -, o autor procura demonstrar a presença de uma relação sinergética entre o processo de construção da cultura organizacional da escola e o desenvolvimento e a inovação educativa.

26. A título ilustrativo, na dissertação de doutoramento produzida por McGhee (1997) - Organizational culture in private higher education: a look at a new private university in post-Soviet Azerbaijan. University of California (Los Angeles). PhD, 234p. (UMI) -, sobre a construção da cultura organizacional num contexto universitário privado num dos países da ex-União Soviética, o autor desenvolve uma análise de cima para baixo (top-down), enfatizando a lógica centralizadora e controladora presente no processo de construção institucional da cultura e identidade organizacional.

27. No âmbito desta linha, sugerimos a consulta da dissertação de mestrado produzida no Canadá por Schill (1992) - Emergent organizational culture: the study of a developing school system. University of Calgary (Canadá). MA, 127p. (UMI) -, onde o autor identifica os valores e as orientaçôes que formam a base da cultura de uma escola, partindo do pressuposto de que tal cultura constitui o reflexo de factores externos (ora mais distantes, ora mais localizados na comunidade) e de factores internos à escola. $\mathrm{O}$ autor conclui que a formação da cultura organizacional não constitui um processo de cima para baixo (top-down), antes traduzindo um percurso inverso, onde os actores se assumem como protagonistas na produção cultural. Numa outra dissertação de doutoramento (Snyder, 1990), intitulada Process and organizational culture considerations when strategically changing a community college: a case study of two examples (University of Maryland College Park. PhD, 413p. UMI), comprovase que a adopção de idênticos estilos de liderança na implementação de programas de acção iguais em duas universidades, com as mesmas características, produz efeitos e resultados distintos ao nível do contexto da acção. Depreende-se desta investigação uma necessidade de se aprofundar o conhecimento das especificidades culturais das organizações escolares, no sentido de melhor prever e regular os processos de mudança educativa.

28. Um dos domínios considerados centrais no estudo da construção da cultura organizacional da escola tem a ver com a análise da integração organizacional dos professores, com a compreensão dos processos de endoculturação nas escolas. A este propósito, registamos, por exemplo, a dissertação de doutoramento desenvolvida no Canadá por Brathwaite (1991), Enculturation: how the work-related behaviours of new employees change to fit the culture of the organization (University of Toronto, Canadá. PhD, 187p. UMI). De igual modo, para uma compreensão mais alargada acerca dos processos de aquisição da cultura organizacional da escola desenvolvidos pelos professores do ensino secundário, sugerimos a consulta da dissertação de doutoramento de Whelan (1993), The acquisition of the socio-organizational culture of the secondary schoolteacher (The Claremont Graduate University. PhD, 257p. UMI).

29. Sobre a exploração dos processos de construção das subculturas dos professores e dos pais, ver, por exemplo, a dissertação de mestrado de Sullivan-Duncan (2000), Parent's and teacher's perceptions of the organizational culture that exists in elementary schools (South Carolina State University. EDD, 94p. UMI). No que respeita à análise comparativa das subculturas dos professores com a dos alunos, sugerimos a consulta da dissertação de doutoramento produzida na Finlândia por Makisalo (1998), Organizational culture in the institute of health care sciences: Teacher's and student's conceptions of the real and desired activity (Kuopion Yliopisto, Finlândia. PhD, 206p. UMI).

30. A obra de Peter McLaren, intitulada Schooling as a ritual performance. Toward a political economy of educational symbols and gestures, e publicada em 1986, constitui, aqui, uma referência obrigatória, pelo facto de desenvolver a sua investigação de índole etnográfica a partir do pressuposto acima enunciado. $\mathrm{O}$ autor exclarece e problematiza o processo de produ-

Educ. Soc., Campinas, vol. 28, n. 98, p. 151-179, jan./abr. 2007

Disponível em <http://www.cedes.unicamp.br> 
Cultura organizacional escolar: apogeu investigativo no quadro de emergência...

ção dos sistemas culturais presentes nas escolas (do contexto canadiano), partindo de uma análise centrada nos rituais dos estudantes e suas interacções com os professores. Vem igualmente a propósito a dissertação de doutoramento desenvolvida por Page (1984), Perspectives and processes: the negotiation of educational meanings in high school classes for academically unsuccessful students (The University of Wisconsin, Madison. PhD, 477p. UMI).

31. Entre um conjunto vasto de trabalhos que adoptaram um ponto de vista multidisciplinar para o estudo da cultura organizacional em contexto escolar, pondo à prova diversos e complementares modelos de análise, destacamos, ilustrativamente, a dissertação de mestrado de Dal Porto (1993) - Superintendent leadership in the organizational culture: a qualitative study. Washington State University. EDD, 223p. (UMI) -, onde o autor adopta o modelo da anarquia organizada de March e Olsen (1979), o modelo do sistema debilmente articulado de Weick (1976), o modelo teórico de Schein (1985) e, ainda, o modelo do interaccionismo simbólico. Registamos, ainda, a dissertação de mestrado desenvolvida por Enomoto (1993) - In-school truancy in a multiethnic urban school examined through organizational culture lenses. The University of Michigan. EDD, 256p. (UMI) -, por representar um caso paradigmático de adopção da multiperspectivação proposta por Meyerson e Martin (1987) (perspectivas integradora, diferenciadora e fragmentadora) na análise da cultura escolar. Para uma análise mais exaustiva desta linha de trabalhos, ver, ainda, as dissertações de doutoramento produzidas no domínio do ensino superior por Gawreluck (1993), Organizational culture in a community college and its interrelationship with leadership and structure (University of Alberta, Canadá. PhD, 406p. UMI); por Tommerup (1993), Adhocratic traditions, experience narratives and personal transformation: an ethnographic study of the organizational culture and folklore of the Evergreen State College, an innovative liberal Arts college (University of California, Los Angeles. PhD, 738p. UMI); e por Mohan (1988), A triangulated approach to the assessment of organizational culture (Kent State University. PhD, 230p. UMI). Entre os trabalhos publicados recentemente, sugerimos um capítulo de livro escrito por Firestone e Louis (1999), intitulado Schools as cultures.

\section{Referências bibliográficas}

AFONSO, A. Políticas educativas e avaliação educacional: para uma análise sociológica da reforma educativa em Portugal (1985-1995). Braga: Instituto de Educação e Psicologia, Universidade do Minho, 1998.

AFONSO, A. Políticas educativas em Portugal (1985-2000): a reforma global, o pacto educativo e os reajustamentos neo-reformistas. In: Catani, A.M.; Oliveira, R.P. (Org.). Reformas educacionais em Portugal e no Brasil. Belo Horizonte: Autêntica, 2000. p. 17-40.

ALLAIRE, Y.; FIRSIROTU, M.E. Theories of organizational culture.
Organizations Studies, London, v. 5, n. 3, p. 193-226, 1984.

ALVESSON, M. Understanding organizational culture. London: Sage, 2002. 
ANTUNES, F. Políticas educativas nacionais e globalização: novas instituições e processos educativos. Braga: CIED, Universidade do Minho, 2004.

APPLE, M.W. Políticas culturais e educação. Porto: Porto, 1999.

APPLE, M.W. Reestruturação educativa e curricular e as agendas neoliberal e neoconservadora: entrevista com Michael Apple. Currículo Sem Fronteiras, Lisboa, v. 1, n. 1, p. 5-33, 2001. Disponível em: $<$ www.curriculosemfronteiras.org.>

APPLE, M. W. 'Endireitar' a educação: as escolas e a nova aliança conservadora. Currículo Sem Fronteiras, Lisboa, v. 2, n. 1, p. 55-78, 2002. Disponível em: <www.curriculosemfronteiras.org>.

BALL, S.J. Directrizes políticas globais e relações políticas locais em educação. Currículo Sem Fronteiras, Lisboa, v. 1, n. 2, p. 99-116, 2001. Disponível em: <www.curriculosemfronteiras.org>.

BATES, R.J. Corporate culture, schooling and educational administration. Educational Administration Quarterly, London, v. 23, n. 4, p. 79-115, 1987.

CIBULKA, J. Ideological lenses for interpreting political and economic changes affecting schooling. In: Murphy, J.; LouIs, K. (Ed.). Handbook of research on educational administration. San Francisco: Jossey-Bass, 1999. p. 163-182.

COHEN, E. et al. Technology and teaming in the elementary school. Sociology of Education, Albany, v. 52, p. 20-33, 1979.

DALE, R. Globalização e educação: demonstrando a existência de uma "cultura educacional mundial comum" ou localizando uma "agenda globalmente estruturada para a educação"?. Educação, Sociedade \& Culturas, Porto, n. 16, p. 133-169, 2001.

DEAL, T.; KENNEDY, A.A. Corporate cultures: the rites and rituals of corporate life. London: Penguin, 1988. (1 ${ }^{\text {a }}$ ed. 1982).

DEAL, T. An organizational explanation of alternative schools failures. Educational Researcher, Washington, v. 4, n. 4, p. 10-16, 1975.

DEAL, T. Alternative schools: struggle for identity. Changing Schools, v. 10, n. 2, p. 8-9, 1982. 
Cultura organizacional escolar: apogeu investigativo no quadro de emergência...

DEAL, T. National commission reports. blueprints for remodeling or ceremonies for revitalizing public schools. Journal of Education and Urban Society, Bervely Hills, v. 17, n. 2, 1985.

DEAL, T. The symbolism of effective schools. In: Westoby, A. Culture and power in educational organizations. Milton Keynes: Open University, 1988. p. 198-222.

DEAL, T.; BALDRIDGE, V. (Ed.). The dynamics of organizational change in education. Berkeley: McCutchan, 1983.

DEAL, T.; KENNEDY, A.A. Culture and school performance. Educational Leadership, Washington, v. 40, n. 5, p. 14-15, 1983.

DEAL, $\mathrm{T}$ et al. Linking knowledge to schools: the process of change in six sites. Andover: The Network, 1977.

ELMORE, R.F. Reform and the culture of authority in schools. Educational Administration Quarterly, Columbus, v. 23, n. 4, p. 60-78, 1987.

ESTÊVÃO, C.V. A agenda oculta da gestão da qualidade total na educação. Organizaçôes \& Trabalho, Lisboa, n. 20, p. 51-61, 1998.

ESTÊVÃO, C.V. Globalização, metáforas organizacionais e mudança educacional: dilemas e desafios. Porto: ASA, 2002.

FOSKETT, N. (Ed.). Managing external relations in schools: a practical guide. London: Routledge, 1992.

KILMANN, R.H. et al. Gaining control of the corporate culture. London: Jossey-Bass, 1985.

LIMA, L. C. A escola como organização e a participação na organização escolar: um estudo da escola secundária em Portugal (1974-1988). Braga: Universidade do Minho, 1992.

LIMA, L.C. Modernização, racionalização e optimização: perspectivas neotaylorianas na organização e administração da educação. Cadernos de Ciências Sociais, Porto, n. 14, p. 119-139, 1994.

LIMA, L.C. Reformar a administração escolar: a recentralização por controlo remoto e a autonomia como delegação política. Revista Portuguesa de Educação, Braga, v. 8, n. 1, p. 57-71, 1995. 
LOUIS, K. et al. Rethinking school improvement. In: Murphy, J.; Louis, K. (Ed.). Handbook of research on educational administration. San Francisco: Jossey-Bass, 1999. p. 251-276.

MARTIN, J. Cultures in organizations: three perspectives. New York: Oxford University; London: Sage, 1992. p. 58-76.

MARTIN, J. Organizational culture: mapping the terrain. London: Sage, 2002.

MARTIN, J.; MEYERSON, D. Organizational culture and the denial, channeling and acknowledgement of ambiguity. In: PONDY, L.R. et al. (Ed.). Managing ambiguity and change. New York: Wiley, 1988. p. 93125.

MARTIN, J. et al. The uniqueness paradox in organizational stories. Administrative Science Quartely, Ithaca, n. 28, p. 438-453, 1983.

MEYER, J.W.; ROWAN, B. Institutional organizations: formal structure as myth and ceremony. American Journal of Sociology, Chicago, n. 83, p. 440-463, 1977.

MEYER, J.W.; SCOTT, R.W. Organizational environments: ritual and rationality. Newbury Park: Sage, 1992 (1 $1^{\text {a }}$ ed. 1977).

ORGANISATION FOR ECONOMIC CO-OPERATION AND DEVELOPMENT (OECD). Governance in transition: public management reforms in OECD countries. Paris: OECD, 1995.

OUCHI, W.G. Teoria Z: como as empresas podem enfrentar o desafio japonês. São Paulo: Nobel, 1986.

OUSTON, J. School efectiveness and school improvement: critique of a movement. In: Bush, T. et al. (Ed.). Educational management: Redefining theory, policy and practice. London: Chapman, 1999. p. 166-177.

PASCALE, R.T.; ATHOS, A.G. Le management est-il un art japonais? Paris: Les Éditions d'Organisation, 1984. (1 ${ }^{\text {a }}$ ed. 1982).

PÉREZ GÓMEZ, A.I. La cultura escolar en la sociedad neoliberal. Madrid: Morata, 1998.

PETERS, T.J.; WATERMAN, R.H. In search of excellence: lessons from America's best-run companies. New York: Harper, 1982. 
Cultura organizacional escolar: apogeu investigativo no quadro de emergência...

PETERS, T.J.; WATERMAN, R.H. Na senda da excelência. Lisboa: Dom Quixote, 1987.

PETTIGREW, A. On studying organizational culture. Administrative Science Quartely, Ithaca, n. 24, p. 570-581, 1979.

PROSSER, J. (Ed.). School culture. London: Sage, 1999.

REYES, P. et al. Delta forces: the changing fabric of American society and education. In: Murphy, J.; LOUIS, K. (Ed.). Handbook of research on educational administration. San Francisco: Jossey-Bass, 1999. p. 183-201. RODRIGUES, M.J. (Coord.). Para uma Europa da inovação e do conhecimento: emprego, reformas económicas e coesão social. Oeiras: Celta, 2000 .

SCHEIN, E.H. Organizational culture and leadership. São Francisco: Jossey-Bass, 1985.

SERGIOVANNI, T.; CARVER, F. O novo exectutivo escolar: uma teoria da administração. São Paulo: EPU, 1974.

SMIRCICH, L. Concepts of culture and organizational analysis. Administrative Science Quartely, Ithaca, n. 28, p. 339-358, 1983.

SPARKES, A. C.; BLOOMER, M. Teaching cultures and school-based management: towards a collaborative reconstruction. In: SMYTH, J. (Ed.). A socially critical view of the self management school. London: The Palmer, 1993. p. 171-189.

ST-GERMAIN, M. Une conséquence de la nouvelle gestion publique: l'émergence d'une pensée comptable en éducation. Éducation et Francophonie, Québec, v. 29, n. 2, p. 1-23, 2001. Disponível em: $<$ www.acelf.ca/revue>.

STOER, S.; CORTESÃO, L. "Levantando a pedra": da pedagogia inter/multicultural às políticas educativas numa época de transnacionalização. Porto: Afrontamento, 1999a.

STOER, S.; CORTESÃO, L. Multiculturalism and educational policy in a global context European perspectives. In: Burbule, N.C.; TORRES, C.A. (Org.). Critical political concepts in the globalization of education. New York: Routledge, 1999b. 
TEIXEIRA, L. A cultura organizacional e o impacto das propostas de mudança em escolas estaduais de Minas Gerais. In: Dourado, L.F.; Paro, V.H. (Org.). Políticas públicas e educação básica. São Paulo: Xamã, 2001.

TORRES, L.L. Cultura organizacional escolar: representaçōes dos professores numa escola portuguesa. Oeiras: Celta, 1997.

TORRES, L.L. Cultura organizacional em contexto educativo: sedimentos culturais e processos de construção do simbólico numa escola secundária. Braga: CIED; Universidade do Minho, 2004.

TORRES, L.L. A cultura organizacional na (re)conceptualização da formação em contextos organizacionais. Cadernos de Ciências Sociais, Porto, n. 21/22, p. 119-150, 2001.

WEICK, K. A psicologia social da organização. São Paulo: Edgard Blucher, 1973. (1 ${ }^{\text {a }}$ ed. 1969).

WHITTY, G.; POWER, S. A escola, o Estado e o mercado: a investigação do campo actualizada. Currículo Sem Fronteiras, Lisboa, v. 2, n. 1, p. 15-40, 2002. Disponível em: <www.curriculosemfronteiras.org>. 